\title{
Valorization of Microcrystalline Cellulose using Heterogeneous Protonated Zeolite Catalyst: An experimental and kinetics approach
}

\author{
Samuel Kassaye \\ Kansas State University \\ Dinesh Gupta \\ Indian Institute of Technology \\ Kamal. K. Pant \\ Indian Institute of Technology Delhi \\ Sapna Jain ( $\sim$ sjain@alasu.edu ) \\ Alabama State University https://orcid.org/0000-0002-0164-1446
}

\section{Research Article}

Keywords: Microcrystalline cellulose, lonic liquid, Hydrolysis, Kinetic modelling

Posted Date: April 14th, 2021

DOI: https://doi.org/10.21203/rs.3.rs-381188/v1

License: (c) (i) This work is licensed under a Creative Commons Attribution 4.0 International License.

Read Full License 


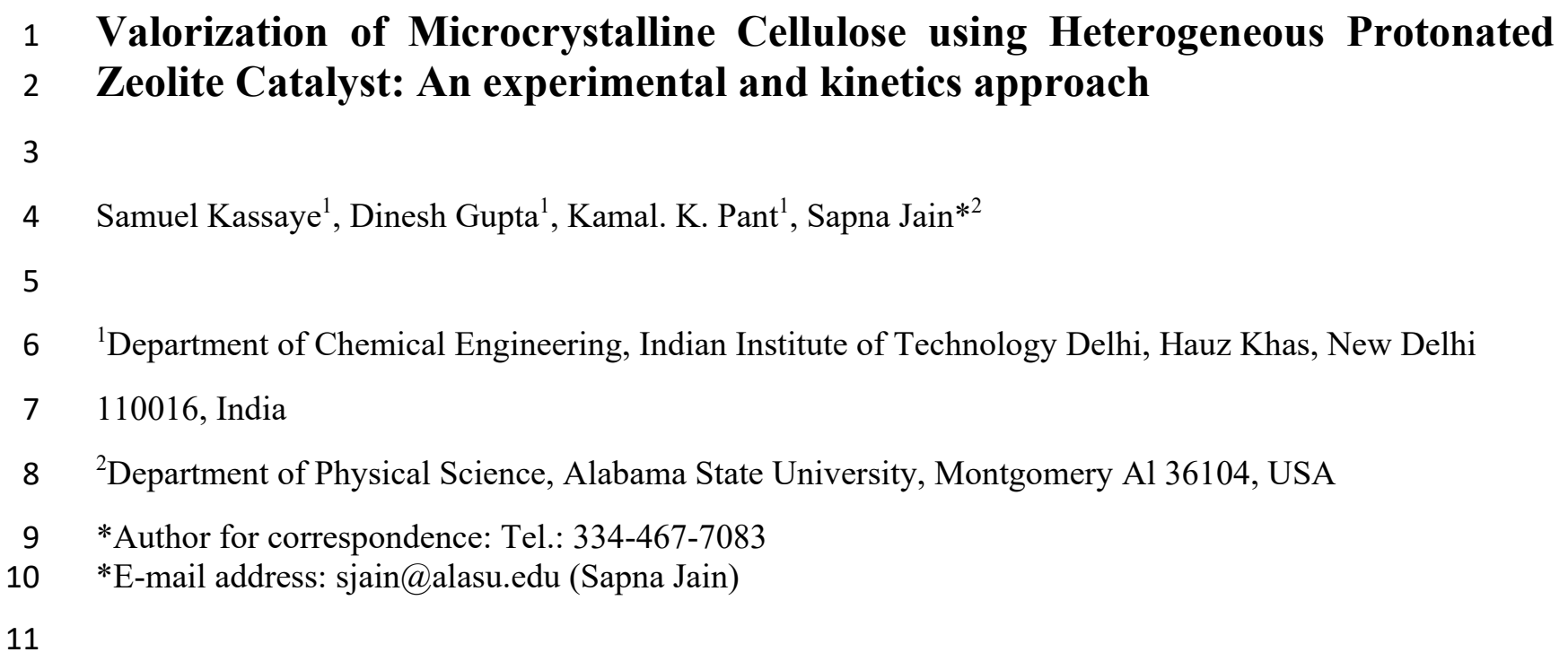

\section{Abstract}

13 This study aims to valorize microcrystalline cellulose (MCC) using protonated zeolite catalysts 14 such as (H-ZSM-5) and Cr/H-ZSM-5 (5 \%) in ionic liquid. The catalytic effect in synergy with 115 butyl-3-methylimidazolium Chloride ([BMIM] $\mathrm{Cl})$ ionic liquid was studied in detail. The total 16 reducing sugar (TRS) was determined using 3, 5-dinitrisalcylic acid (DNS) array method. The 17 catalysts were characterized using techniques such as Fourier transform infrared (FT-IR), X-ray diffraction analysis (XRD), temperature-programmed desorption of ammonia ( $\left.\mathrm{NH}_{3}-\mathrm{TPD}\right)$, and BET-surface area analyzer. H-ZSM-5 effectively depolymerized cellulose with a maximum yield 20 of $70 \%$ total reducing sugar (34\% glucose, $8 \%$ fructose, and 4.5\% 5-HMF) Cr/H-ZSM-5 catalyst 21 dehydrates fructose to 5-HMF with a yield of 53\%. The use of ionic liquid significantly reduced 22 the activation energy of formation and decomposition. The activation energy determined in 23 cellulose hydrolysis was $85.83 \mathrm{KJ} \mathrm{mol}^{-1}$ for a reaction time of $180 \mathrm{~min}$ while the decomposition 24 energy was found to be $42.5 \mathrm{~kJ} \mathrm{~mol}^{-1}$. 


\section{1. Introduction}

Efficient and Economic conversion of lignocellulosic biomass (LCB) to value-added chemicals in integrated biorefinery is believed to reduce the dependency on a nonrenewable resource such as fossil fuel. LCB is a promising feedstock for the biorefinery industry to produce biofuel and valuable chemicals from renewable sources [1]. Successful utilization of biomass demands the effective conversion of the cellulosic portion of LCB to develop integrated biorefinery to produce biofuel and chemicals economically. The hydrolysis of cellulose strongly depends on its properties such as degree of polymerization and crystallinity. The utilization of lignocellulosic biomass depends on the level of success achieved on hydrolysis of the cellulose into its monomeric form, glucose [2]. However, cellulose is the most recalcitrant and well-known crystalline biopolymer due to its extensive intra and inter-hydrogen bonding network. Cellulose is a structurally linear polymer composed of glucose monomers joined together by $\beta-1$, 4-glycosidic linkage [3]. Therefore, it is difficult to dissolve and subsequently hydrolyze cellulose using conventional organic solvents including water and ethanol [4] [5].

The hydrolysis of cellulosic biomass is carried out using an enzymatic approach accompanied by a high glucose yield at moderate reaction conditions. Enzymatic hydrolysis has several disadvantages related to the high cost of enzymes, limited cellulose conversion, and scalability challenges [3]. Hydrolysis of cellulose using acidic catalysts such as liquid acids including mineral and organic acids is another alternative option [6]. Mineral acids are highly efficient in breaking $\beta$-1,4-glucosidic linkage [7] [8]. However, this method has several drawbacks: reaction product decomposition, difficulty in the product, and catalyst separation. Mineral acid catalysts are also known to cause reactor corrosion, costly post- treatment, challenges in recycling catalysts and consumption of a large amount of neutralizing agents [9] [10]. As a result, attempts are underway 
to apply solid acid catalysts to convert lignocellulosic biomass to bio-chemicals. The application

51 of ionic liquids further improves this approach. Some selected ionic liquids have inherent

52 characteristics to dissolve cellulose and disrupt the hydrogen bonding network effectively.

53 Ionic liquids (ILs) are low melting point organic salts that can be utilized both as solvents and 54 catalysts to convert lignocellulosic biomass [11]. The suitability of ILs for biomass utilization is 55 attributed mainly to their tunable Physico-chemical properties such as viscosity, polarity, and thermal 56 stability. ILs act as non-volatile polar solvents and it can dissolve the complex cellulosic materials. The 57 use of ILs allows production flexibility with high efficiency while eliminating the use of undesirable 58 volatile solvents. In this regard, solid acid catalysts such as zeolites, ion exchange resins, and zirconia 59 are considered an alternative chemo-catalytic approach for cellulose depolymerization. The use of 60 zeolite based solid acid catalysts have tremendous advantages compared to homogeneous catalysts

61 such as easy separation, recyclability, and adjustable surface acidity [12].

62 Zeolite catalysts have been modified and used in industrial processes as milestones in history and 63 have brought profound changes in the petrochemicals industry. For example, Zeolite Y's use in the 64 Fluid Catalytic Cracking (FCC) process significantly increased fuel production efficiency. HZSM655 , which has 8 to 10 -member ring with pore-size between 0.5 and $56 \mathrm{~nm}$, is well suited for bio66 refinery. However, cellulose insolubility in aqueous media has been the foremost hurdle to apply 67 zeolites as solid acid catalysts due to solid-solid formation which limits mass transfer and 68 reactivitiy. However, ionic liquids with unique properties to dissolve cellulose and reduce its 69 crystallinity have been a choice to convert cellulose to value-added chemicals [13] [14].

70 Zeolites inherently possess both Bronsted and Lowry as well as Lewis acid sites. These acidic sites

71 help catalyze and promote hydrolysis of cellulose, isomerization of glucose, and fructose 72 dehydration [15]. H-ZSM-5 catalyst has been the choice of this study due to its inherent properties, 
73 such as strong and active acid sites suitable for a catalyst with a porous structure and larger surface

74 area. These properties enhance and facilitates the depolymerization of cellulose to produce bio-

75 chemicals. In this research work, the catalytic effects of H-ZSM-5 and $\mathrm{Cr} / \mathrm{H}-\mathrm{ZSM}-5$ (5 \%) were

76 studied to depolymerize MCC. The experimental results showed that the synergy between ionic

77 liquid and H-ZSM-5 improved cellulose conversion and the yield of the desired bio-chemicals.

78 Results showed that this approach generated a $70 \%$ yield of total reducing sugar (34\% glucose,

$798 \%$ fructose and $4.5 \% 5-\mathrm{HMF}$ ) at moderate temperature and atmospheric pressure. Besides, ionic

80 liquid presence significantly reduced the activation energy of the formation and decomposition of 81 sugar.

\section{2. Materials and Methods}

\section{$83 \quad 2.1$ Materials}

84 All the chemicals used were of analytical grade (purity 99.9\%). Microcrystalline cellulose extra

85 pure, the average particle size of $90 \mu \mathrm{m}$ is purchased from Alfa Aesar (A Johnson Matthey

86 Company, Heysham, Lancashire, United Kingdom). As reported in our previous research work

87 [16], the original MCC's initial crystallinity index was found to be $76 \%$, which reduced to $42 \%$

88 due to the influence of the ionic liquid. 1-Chlorobutane, N-methyl imidazole, toluene, acetone

89 acetonitrile, ethyl acetate, 3,5-dinitrisalcylic acid, sodium hydroxide, sodium potassium tartrate

90 phenol, acetonitrile, cellulose and isopropanol were purchased from Fisher Scientific (Anand

91 Bhuvan, Princess Street Mumbai, India), H-ZSM-5 with Si/Al ratio of 30 was obtained from Sud-

92 chemie India. [BMIM] $\mathrm{Cl}$ ionic liquid was prepared and characterized as reported in our previous

93 work [16].

$94 \quad 2.2$ Methods

$95 \quad$ 2.2.1 Catalysts Synthesis and Characterization 
Chromium-impregnated H-ZSM-5 (Cr/H-ZSM-5) catalyst was prepared using wet impregnation

97 method in which H-ZSM-5 was mixed with chromium precursor $\left(\mathrm{CrCl}_{3} .6 \mathrm{H}_{2} \mathrm{O}\right)$ in 50 ml distilled water [17]. The mixture was stirred vigorously for $3 \mathrm{~h}$ at $80^{\circ} \mathrm{C}$ and then, the excess solvent was removed by rotary evaporator at reduced pressure. Subsequently, the sample was dried overnight at $120^{\circ} \mathrm{C}$ and calcined at $500{ }^{\circ} \mathrm{C}$ for $5 \mathrm{~h}$. The catalysts were characterized using FTIR, XRD, BET surface area, ammonia TPD and TGA. The thermal properties of both catalysts were studied using thermo-gravimetric analysis (TGA). The analysis was performed using nitrogen gas as a purge gas at a flow rate of $30 \mathrm{ml}$ per min with a heating rate of $20{ }^{\circ} \mathrm{C}$ per min from 30 to $1,000{ }^{\circ} \mathrm{C}$. total acid strength and acid site distribution on the surface of both catalysts using the Micromeritics

Pulse Chemisorb 2720 instrument. The chemisorb instrument is equipped with a quartz reactor 107 and a thermal conductivity detector (T.C.D). The sample catalyst $(0.2 \mathrm{~g})$ was pre-treated at $250^{\circ} \mathrm{C}$ 108 for $2 \mathrm{~h}$ with a continuous flow of pure helium gas to remove the moisture content at room 109 temperature. The sample was then saturated with $10 \%$ ammonia gas for adsorption for $1 \mathrm{~h}$. After 110 complete saturation, physisorbed ammonia was removed by flowing helium for $30 \mathrm{~min}$. The TPD 111 was carried out in a stream of helium gas, raising the temperature from $50^{\circ} \mathrm{C}$ to $980{ }^{\circ} \mathrm{C}$ at the rate 112 of $10{ }^{\circ} \mathrm{C}$ per min. The desorption process of ammonia was monitored using a T.C.D detector and 113 the amount of total desorbed ammonia was obtained from the integrated peak area of the TPD 114 profiles relative to the calibration curve.

\section{$115 \quad$ 2.2.2 Catalytic Hydrolysis}

116 The hydrolysis of MCC was performed using a batch reactor of $250 \mathrm{ml}$ size where the dissolution 117 of $\mathrm{MCC}$ was performed in [BMIM] $\mathrm{Cl}$ ionic liquid with 1:20 w/w proportion. The stirring was 
118

119

120

121

122

123

124

125

126

127

128

129

130

131

132

133

134

135

136

137

138

carried out continuously for $30 \mathrm{~min}$ until the mixture turns homogeneous. Then, $5 \mathrm{~mL}$ of distilled water and H-ZSM-5 (1:2 w/w ratio of MCC to H-ZSM-5) was added and the solvent was reflexed back to the reactor using a condenser. On the completion of the reaction time, the reaction mixture was quenched using an ice bath. Then, the catalyst and the hydrolysate were separated using vacuum filtration process. The hydrolysate was centrifuged at $10,000 \mathrm{rpm}$ for $10 \mathrm{~min}$ and then stored in a refrigerator for further analysis.

\subsubsection{Hydrolysis Product Analysis}

The samples were analyzed using dinitrosalicyclic acid (DNS) reagent in UV-Vis Spectroscopy for TRS yield while HPLC was used to determine the yield of sugars and dehydration products. DNS analysis hydrolysate was mixed with DNS reagent in 1:2 v/v ratio and boiled for 10 minutes in a water bath. The resulting solution was cooled using an ice bath and the analysis was carried out by measuring the absorbance of the sample using UV-Vis spectroscopy (CARY 100Conc) at $540 \mathrm{~nm}$ wavelength. The total reducing sugar yield was determined from the calibration curve formed using four-point concentration of standard glucose solutions. The yield of TRS was calculated using Equation 1.

$$
\text { TRS Yield }(\%)=\frac{\text { Mass of reducing sugar } \times \frac{162}{180} \times 100}{\text { Mass of dry cellulose }}
$$

Fructose, glucose, and 5-HMF were analyzed using high-performance liquid chromatography (HPLC). The HPLC analysis was performed using Agilent technology 1200 infinity equipped with Bio-Rad Aminex HPx-87H 300 x 7.8 mm columns, UV-detector for sugar dehydration product and RI detector for sugar products. The eluent was $5 \mathrm{mM}$ sulphuric acid with a flow rate of $0.6 \mathrm{ml}$ per minute and the injection volume was $20 \mu \mathrm{l}$. The identification of products in the sample was 
139 performed using a pure form of the products to determine retention time and calibration curve

140 formation. The 5-HMF was calculated as given below in Equation 2.

141

$$
5-\mathrm{HMF} \text { Yield }(\%)=\frac{\text { moles of } 5-\mathrm{HMF} \text { produced } \times 100}{\text { moles of cellulose feed }}
$$

\section{3. Result and Discussion}

\section{$143 \quad$ 3.1 Catalysts Characterization}

144 The catalyst was characterized using FTIR, XRD, BET surface area, ammonia TPD and TGA 145 analysis as discussed below.

\section{$146 \quad$ 3.1.1 FT-IR Analysis}

147 H-ZSM-5 and Cr/H-ZSM-5 catalysts were characterized by FT-IR method to study the effect of 148 chromium metal incorporation into the framework structure of the H-ZSM-5 catalyst. The FTIR 149 spectra of H-ZSM-5 and Cr/ H-ZSM-5 catalysts range between 500 and $2000 \mathrm{~cm}^{-1}$ shown in Figure 150 1. The result shows that the position of sensitive structural bands of H-ZSM-5 and Cr/H-ZSM-5 151 catalysts have similar positions. This implies that chromium metal incorporation into the zeolite 152 structure was insignificant to alter the basic zeolite structure and functional groups. The internal 153 vibrations of $\mathrm{SiO}_{4}$ and $\mathrm{AlO}_{4}$ are represented by the absorption bands at 1,088 and $810 \mathrm{~cm}^{-1}$, 154 respectively [18]. Similarly, the bands near 540 and $1225 \mathrm{~cm}^{-1}$ are assigned to the double ring 155 vibration and asymmetric stretching. 
158 Figure 2 shows the XRD-spectra pattern of H-ZSM-5 and Cr\H-ZSM-5. The XRD data analysis 159 was used to study the effect of chromium metal incorporation on the framework structure of the H-ZSM-5 catalyst. The intensity and the number of diffraction peaks of both catalysts were similar 161 and there is no indication of significant change in the XRD pattern. However, the peak of the $\mathrm{Cr} / \mathrm{H}-$ 162 ZSM-5 catalyst has shown a slight shift to the left. According to the Bragg equation, this shift in 163 the peak of $\mathrm{Cr} / \mathrm{H}-\mathrm{ZSM}-5$ catalyst is attributed to the increase in interplanar d-spacing due to 164 chromium metal presence in the framework [19]. This indicates that the bigger lattice parameters 165 representing the inclusion of atoms of different diameters. However, extra diffraction peaks were 166 not observed representing uniform dispersion of chromium throughout the zeolite framework 167 structure [20].

\subsubsection{BET Analysis}

The BET surface area analysis for H-ZSM-5 and Cr/H-ZSM-5 is given in Table 1. According to 170 the results, the surface area of H-ZSM-5 decreased after the impregnation of chromium metal.

171 Impregnation of chromium metal to H-ZSM-5 led to a decrease in surface area from 270 to 248

$172 \mathrm{~m}^{2} \mathrm{~g}^{-1}$ due to the partial pores blocking H-ZSM-5 structural support by chromium metal [21].

\section{$173 \quad$ 3.1.4 Ammonia-TPD Analysis}

174 The acid site property of the catalysts was studied using temperature-programmed desorption of 175 ammonia (Ammonia-TPD). As presented in Figure 3, the catalysts' acid site distribution was 176 determined using the desorption peaks. The result showed the effect of chromium metal 177 impregnation into the framework structure on the acidity of H-ZSM-5. The entire surface acid sites 178 of $\mathrm{Cr} / \mathrm{H}-\mathrm{ZSM}-5$ qualitatively increased compared to H-ZSM-5 implying the presence of additional 179 acid sites due to the inclusion of chromium into the H-ZSM-5 structure [22]. For H-ZSM-5, the 
180 low-temperature peak was observed at a temperature between $150-300{ }^{\circ} \mathrm{C}$ while the hightemperature peak was observed in between $300-500{ }^{\circ} \mathrm{C}$ representing the low and high desorption

182 peaks, respectively.

183 Similarly, Cr/H-ZSM-5 catalyst showed the acid sites distribution at a low temperature of 200 $184300{ }^{\circ} \mathrm{C}$ while the high-temperature peak at $350-650{ }^{\circ} \mathrm{C}$. The peak at low and high temperature 185 indicates the presence of weak and strong acid sites, respectively. In general, the incorporation of 186 chromium metal into the frameworks of H-ZSM-5 increased both the strong and the weak acid 187 sites. However, the effect on strong acid sites is more significant than the weak acid sites which 188 are consistent with the literature [21].

\subsection{Hydrolysis of MCC}

In a preliminary study, hydrolysis of MCC was performed in the absence of H-ZSM-5 catalyst, 191 [BMIM] $\mathrm{Cl}$ and prior dissolution for a reference purpose. Compared with the reference, the 192 hydrolysis reaction was significantly influenced by the prior dissolution in ionic liquid and the 193 catalytic amount of H-ZSM-5. In this condition, 70\% maximum yield of TRS was achieved at a 194 temperature of $180 \mathrm{oC}$, reaction time of $180 \mathrm{~min}$, and catalyst to substrate loading ratio of 2:1

$195(\mathrm{w} / \mathrm{w})$. The high sugar yield from the prior dissolution process is attributed to the structural change 196 from microcrystalline to amorphous cellulose due to the ionic liquid effect [5]. The ionic liquid 197 used was potent enough to break the hydrogen bonding networks which hold the cellulose strand 198 together. As a result, cellulose's crystallinity reduced significantly, facilitating the accessibility of 199 cellulose to the acid sites of the H-ZSM-5 catalyst. The exposure of the acid sites breaks the 200 glycosidic bonds of the glucose monomers. In similar experimental work under identical 201 conditions except for the absence of catalyst, hydrolysis reaction yielded $6 \%$ of TRS, exceptionally 
202 low, signifying the catalyst for effective yield. Besides, hydrolysis without prior dissolution 203 resulted in $8 \%$ TRS yield. In this case, the low yield of TRS is due to solid-solid interactions of 204 cellulose substrate and H-ZSM-5. Prior dissolution of cellulose decreased the crystallinity and 205 degree of polymerization, which improved the H-ZSM-5 catalyst and the substrate's interaction. 206 In this condition, the dissolved MCC easily migrate to the catalyst's active surface to cause the 207 breakdown of the glycosidic bonds to release the sugar monomers. The higher conversion of 208 cellulose and maximum yield of TRS was obtained due to improved interaction of MCC substrate 209 with the catalyst.

210 Figure 3 shows, the hydrolysis of MCC and the effect of temperature on the yield of hydrolysis 211 products. The effectiveness of the hydrolysis of MCC in the catalytic effect of H-ZSM-5 in the 212 presence of [BMIM] $\mathrm{Cl}$ ionic liquid was studied based on TRS, glucose, fructose and 5-HMF yield. 213 The hydrolysis reaction results at the different temperatures indicated that the maximum yield of 214 TRS was obtained at $180^{\circ} \mathrm{C}$ whereas for glucose the maximum yield was obtained at $190{ }^{\circ} \mathrm{C}$. The 215 TRS yield showed an increase as temperature raised from $160{ }^{\circ} \mathrm{C}$ to $180^{\circ} \mathrm{C}$. However, the yield 216 showed a decreasing trend as temperature further increased due to the decomposition of TRS. As 217 seen in Figure 4, the hydrolysis of MCC is significantly affected by reaction temperature and time. 218 The results implied a maximum of $70 \%$ TRS comprising of $34 \%$ glucose, $8 \%$ fructose and $4.5 \%$ 2195 -HMF at a temperature of $180{ }^{\circ} \mathrm{C}$ and hydrolysis time of $180 \mathrm{~min}$. Similarly, the effect of 220 hydrolysis time on the yield of TRS, glucose and fructose at different temperatures showed that 221 the product yield is significantly affected by reaction time. The yield of TRS increased with time 222 and reached a maximum of $180 \mathrm{~min}$ of hydrolysis time. Afterward, the TRS yield decreased due 223 to the decomposition of sugars because of extended reaction time. As can be observed from Figure 224 2, the depolymerization of cellulose using H-ZSM-5 catalyst in [BMIM] $\mathrm{Cl}$ ionic liquid results in 
225 an increasing trend and decreases at extended time depolymerization. For cellulose hydrolysis 226 carried out for a run time of $180 \mathrm{~min}$ and at a catalyst to substrate ratio of 2:1 resulted in a sharp 227 increase in TRS yield as the temperature increased from $160{ }^{\circ} \mathrm{C}$ ( $44 \%$ yield of TRS) to $180{ }^{\circ} \mathrm{C}$ 228 (70\% yield of TRS). However, further raising the temperature from $180{ }^{\circ} \mathrm{C}$ to $200{ }^{\circ} \mathrm{C}$ deceased the 229 yield to $60 \%$. This is caused due to the decomposition of sugars such as glucose and fructose as 230 the temperature is increased above $180^{\circ} \mathrm{C}$ for $180 \mathrm{~min}$ of hydrolysis time.

231 For a comparative study, the experiments were carried out in a round bottom flask kept in an oil 232 bath. A typical experimental process is as follows: $0.1 \mathrm{~g}$ cellulose is dissolved in $2.0 \mathrm{~g}$ [BMIM] Cl 233 at predetermined dissolution temperature and time, and then a catalytic amount of H-ZSM-5 234 catalyst and $5 \mathrm{ml}$ of distilled water was added to the mixture. The Depolymerization of MCC was 235 carried out via two main steps; first through the prior dissolution of $\mathrm{MCC}$ in [BMIM] $\mathrm{Cl}$ ionic 236 liquid followed by hydrolysis by solid acid catalysts, H-ZSM-5 and Cr/H-ZSM-5. The purpose of 237 prior dissolution with [BMIM] $\mathrm{Cl}$ ionic liquid was to break the structural network of hydrogen 238 bonding in cellulose to achieve easier interaction between catalyst and substrate. Preliminary 239 experimental results were compared to the two catalysts for effective depolymerization of MCC 240 for further investigation. It was found that the H-ZSM-5 catalyst showed better catalytic activity 241 to depolymerize MCC a maximum yield of $70 \%$ total reducing sugar while the $\mathrm{Cr} / \mathrm{H}-\mathrm{ZSM}-5$ 242 catalyst yielded a maximum of 55\%. However, $\mathrm{Cr} / \mathrm{H}-\mathrm{ZSM}-5$ achieved a higher yield of 5-HMF 243 from fructose (53\%) while H-ZSM-5 gives a maximum yield of $31 \%$ with identical reaction 244 condition. The weak catalytic activity $\mathrm{Cr} / \mathrm{H}-\mathrm{ZSM}-5$ to depolymerize $\mathrm{MCC}$ to total reducing sugar 245 is due to a reduction in Bronsted acid sites due to chromium metal inclusion which generally 246 increases the Lewis acidity at the expense of Bronsted acid sites. For cellulose hydrolysis, higher 
247 Bronsted acidity is required to cleave the glycosidic bond while for sugar dehydration, both 248 acidities' optimized acid sites play an essential role.

249 In transforming lignocellulosic biomass to value-added chemicals such as 5-HMF and LA, fructose 250 is considered the ideal substrate with more straightforward conversion and excellent yield of 5251 HMF using a wide range of homogeneous as well as heterogeneous catalysts. For instance, 252 chromium chloride $\left(\mathrm{CrCl}_{2}, \mathrm{CrCl}_{3}\right)$ and copper chloride catalysts in an ionic liquid have been 253 reported to be effective for dehydration of sugars to form 5-HMF with a maximum yield of $81 \%$ 254 from fructose and 70\% using glucose [23][24]. However, the challenge in separation and the high 255 level of chromium toxicity hindered the practical production of 5-HMF. Heterogeneous acid 256 catalysts have easy recovery and production sustainability making them more promising for 257 practical applications in large-scale production than homogenous catalysts [25]. Therefore, 258 catalytic dehydration of fructose to 5-HMF using chromium metal impregnated on H-ZSM-5 259 support (5 \% Cr/H-ZSM-5) was tested and the resulted in 87\% conversion and 55\% yield 5-HMF 260 in [BMIM] Cl-water reaction media. In this study with identical reaction condition, the yield of 5261 HMF using $\mathrm{Cr} / \mathrm{H}-\mathrm{ZSM}-5$ catalyst was found to be effective compared with the yield obtained from 262 H-ZSM-5 catalyst (H-ZSM-5). Therefore, further investigation was carried out to study the effect 263 of temperature and dehydration time on 5-HMF yield.

264 The effect of temperature and reaction time on the dehydration of fructose catalyzed by $\mathrm{Cr} / \mathrm{H}-$ 265 ZSM-5, using [BMIM] Cl-water as a solvent, has been studied. The yield of 5-HMF showed a 266 pattern of increasing and then decreasing with time at all temperatures studied. At $160{ }^{\circ} \mathrm{C}$, the yield 267 of 5-HMF increased gradually to $34 \%$ up to $60 \mathrm{~min}$, while at $180^{\circ} \mathrm{C}$ it increased rapidly to $53 \%$ 268 after $30 \mathrm{~min}$, showing that higher temperature increased the yield of 5-HMF and decreased the 269 dehydration time required. This was further confirmed at $200{ }^{\circ} \mathrm{C}$ with a of yield $47 \% 5-\mathrm{HMF}$ at 15 
270 min of dehydration time. The maximum yield was achieved at a temperature of $180{ }^{\circ} \mathrm{C}$ and $30 \mathrm{~min}$

271 of reaction time. When the dehydration reaction time was extended over $30 \mathrm{~min}$, the yield of 5-

272 HMF decreased significantly due to decomposition of 5-HMF. The degradation products contain

273 levuilinic acid, formic acid and soluble polymers as observed from HPLC analysis. However, the

274 separated products were exceedingly small to be quantified. In the case of soluble polymers, a

275 wide range of products are possibly available, which is very difficult to obtain the accurate

276 molecular structure and determine the exact product type [25].

277 The reaction temperature and time have a significant influence on the conversion of glucose to 5-

278 HMF. The conversion of glucose to 5 -HMF at a temperature of $200{ }^{\circ} \mathrm{C}$ and $60 \mathrm{~min}$ of reaction

279 time yielding a maximum yield of $24 \% 5-\mathrm{HMF}$ was achieved. The results suggested that as

280 temperature increased, the yield of 5-HMF also increased initially and then followed a decreasing

281 pattern at extended reaction time due to the formation of undesired products such as insoluble

282 humin and soluble polymers [26]. Moreover, the formation of 5-HMF from glucose at $160^{\circ} \mathrm{C}$ and

$283180^{\circ} \mathrm{C}$ at 120 min of reaction time resulted in maximum yield of 17 and $19.5 \% \mathrm{HMF}$, respectively.

284 The dehydration of glucose is relatively complex compared with fructose due to the six-membered

285 pyranoside structure. For this reason, the dehydration of glucose to 5-HMF undergoes an additional

286 step of isomerization of glucose to fructose before the dehydration reaction to form 5-HMF using

287 Cr/H-ZSM-5 catalyst.

288 3.2.3 Mechanism of MCC Hydrolysis

289 During the hydrolysis of MCC, two steps are essential: the dissolution of MCC in [BMIM] Cl

290 ionic liquid and subsequent hydrolysis in the presence of water as a co-solvent using catalytic

291 amount of H-ZSM-5 catalyst. The purpose of dissolution of MCC alone in the ionic liquid is 
292 primarily to overcome cellulose's recalcitrant behavior and break the hydrogen bonding 293 networking in the cellulose strand. This step is essential to improve the accessibility of $\beta-1,4-$ 294 glycosidic linkages between the glucose and create contact between the substrate and catalyst 295 within the reaction media. Besides, prior dissolution helps simplify the structural complexity of 296 cellulose resulting from higher crystallinity and a more significant degree of cellulose 297 polymerization to ease hydrolysis. Mechanistically, the chlorine ions of the ionic liquid are 298 efficient in forming a new hydrogen bonding with the hydroxyl groups of cellulose while the 299 cations prevent the crosslinking of cellulose in the dissolution process. The cations form a linkage 300 with the oxygen of the broken hydroxyl groups of the cellulose and serve as electron acceptors 301 (Figure 6).

302 The hydrolysis of MCC is described by the Saeman model [27] that the reaction kinetics follows 303 two pseudo-homogeneous consecutive first-order reaction. The degradation products are mainly 304 5-HMF and humins. The Mechanism of MCC hydrolysis over H-ZSM-5 catalyst is like the 305 hydrolysis of cellulose in the presence of homogeneous acidic catalysts such as sulphuric acids. 306 The glycosidic bonds in cellulose polymer are broken by Bronsted acid sites similar to $\mathrm{H}^{+}$ions of 307 acidic solution breaks the bond to release the glucose monomers through binding with the 308 glycosidic oxygen atom leading to hydrolysis of MCC to simple sugars. $\mathrm{H}+$ cations generated in309 situ from the Bronsted acid sites of zeolite were the key active species for the effective hydrolysis 310 of cellulose over H-ZSM-5 and the Lewis acid sites do not exhibit high activity as reported from 311 FT-IR through pyridine adsorption [19]. In addition to the catalyst, the $\mathrm{H}^{+}$molecules produced 312 from the dissociation of water (co-solvent) participate in the hydrolysis reaction, facilitating the 313 glycosidic bond's cleavage.

\subsubsection{Kinetic modeling of MCC depolymerization}


315 Valorization of lignocellulosic biomass requires understanding the mechanism and kinetics of the 316 complex cellulose hydrolysis reaction [28]. The complexity of cellulose hydrolysis emerged from

317 the recalcitrant behavior of cellulose which requires harsh reaction conditions. The hydrolysis 318 products (sugars) have high reactivity that suffers from further decomposition at sever reaction 319 conditions. The incompatibility between the cellulose stability and highly reactive hydrolysis 320 products complicates understanding the reaction mechanism and kinetics of cellulose hydrolysis. 321 However, understanding the mechanism and kinetics of hydrolysis reaction is especially important 322 for process design and optimization. The kinetic modeling for cellulose hydrolysis in the 323 synergetic effect of H-ZSM-5 catalyst and [BMIM] $\mathrm{Cl}$ ionic liquid has been studied to investigate 324 the ionic liquid's effect on the rate of reaction, activation energy and mechanism of hydrolysis.

325 The yield data of TRS were obtained experimentally and data generated from the mathematical 326 model (Eqn 1.4), the activation energy and reaction rate constants ( $\mathrm{k}_{1}$ and $\left.\mathrm{k}_{2}\right)$ were calculated and 327 compared, and the results are presented in Figure 3. The experiments were performed over a wide 328 temperature range $\left(140\right.$ to $200{ }^{\circ} \mathrm{C}$ ) and hydrolysis run time (0 to $\left.180 \mathrm{~min}\right)$. The kinetic model used 329 is a model developed by Saeman for cellulose hydrolysis, and the present study assumes 330 irreversible pseudo-homogeneous first-order reactions [27]. The estimate of the kinetic parameters 331 is performed using Polymath 6.0 software. The following assumptions were taken into 332 consideration for model development:

333 1. The first step in depolymerization of microcrystalline cellulose is the cleavage of $\beta-(1,4)$ 334 glycosidic bonds followed by decomposition of TRS to other products 5-HMF and humin.

335 2. The reaction rate equations were developed based on the Saeman model considering all the 336 model's assumptions [27]. 
337 3. The TRS concentration was based on MCC's hydrolysis reaction that includes the major 338 depolymerization products intermediate sugars and oligomers.

4. Mass transfer on the reaction kinetics was insignificant due to the complete dissolution of cellulose in [BMIM] $\mathrm{Cl}$ ionic liquid media before depolymerization reaction.

5. It is assumed that dissolved cellulose diffuses into the internal pores of zeolite and the glycosidic bonds of cellulose then extend into the vicinity of Bronsted acid sites where catalytic depolymerization takes place [29].

344 Hydrolysis of lignocellulosic biomass is an overly complex reaction comprising of formation and 345 decomposition of sugars. Therefore, a simplified kinetic model is used to describe the formation 346 and decomposition of sugar products from cellulose's hydrolysis. The model proposes that 347 cellulose depolymerization involves the hydrolysis of cellulose to reducing sugar and subsequent 348 degradation of sugar to furan chemicals and humin. The reaction scheme for depolymerization of 349 cellulose is shown in Equation 1.1 while the reaction rate constant for thesecond series reaction 350 i.e., TRS decomposition is given in Equation 1.2.

353 The formation rate of reducing sugars (B) with respect to depolymerization time is represented by 354 Equation 1.4. The integration of Equation 1.4 (considering the following boundary conditions at $t$ $355=0, \mathrm{C}_{\mathrm{B}, 0}=0$ ) with respect to time gives Equation 1.6 which was used to represent the concentration 356 of total reducing sugar production as a function of time and used to calculate the reaction constants $357\left(\mathrm{k}_{1}\left(\min ^{-1}\right)\right.$ and $\left.\mathrm{k}_{2}\left(\mathrm{~min}^{-1}\right)\right)$. The Arrhenius equation describes the correlation of reaction rate 358 constants with the temperature. The activation energies were calculated from the Arrhenius 
359 equations with a reference temperature. For a batch reaction rate of formation of the reactions is 360 given as follow:

$$
-\mathbf{r}_{\mathrm{A}}=\mathrm{k}_{1} \mathrm{C}_{\mathrm{A}}
$$

$$
\mathbf{r}_{\mathrm{B}}=\mathrm{k}_{1} \mathrm{C}_{\mathrm{A}}-\mathrm{k}_{2} \mathrm{C}_{\mathrm{B}}
$$

The concentration of TRS with time can be calculated as shown in Eqn 1.6 below:

$$
\mathbf{r}_{\mathrm{C}}=\mathrm{k}_{1} \mathrm{C}_{\mathrm{A}}
$$

Where $\mathrm{C}_{\mathrm{A}}$ is the cellulose concentration $\left(\mathrm{mg} \mathrm{ml}^{-1}\right), \mathrm{C}_{\mathrm{A} 0}$ is the initial concentration of cellulose (mg

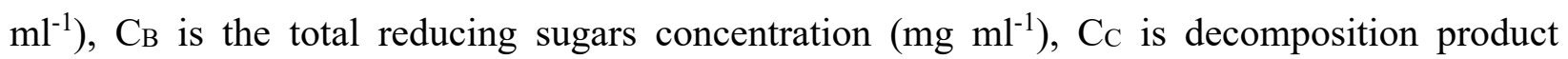
concentration and ' $\mathrm{t}$ ' is the depolymerization reaction time (min).

\subsubsection{Formation and Degradation of TRS}

371 promising approach to overcome the recalcitrant nature of cellulose for a potential scale-up to the

372 bio-refinery scheme. The presence of [BMIM] $\mathrm{Cl}$ ionic liquid improved the yield of interest

373 products from microcrystalline cellulose's depolymerization. The role [BMIM] $\mathrm{Cl}$ was significant

374 mainly for three reasons: (1) [BMIM] $\mathrm{Cl}$ dissolved cellulose entirely within the given substrate

375 loading, (2) the chloride ions in the ionic liquid played the role of base and nucleophile that

376 promoted the isomerization of glucose to fructose and (3) $[\mathrm{BMIM}]^{+}$of the ionic liquid stabilize

377 dehydration products from further decomposition [30]. Dissolution temperature and time showed 
378 a profound effect on reducing the crystallinity index and degree of cellulose polymerization.

379 Higher the crystallinity and degree of polymerization of cellulose, the less the reactivity to 380 depolymerize to sugar monomers. Therefore, it is imperative to dissolve cellulose and reduce its 381 crystallinity to hydrolyze the substrate effectively. The reduction in crystallinity was achieved 382 through the prior dissolution of cellulose in an ionic liquid followed by the hydrolysis reaction 383 using the catalytic effect of the H-ZSM-5 catalyst.

384 A kinetic model was constructed based on calculating the best-fit reaction coefficients for $\mathrm{k}_{1}$ and $385 \mathrm{k}_{2}$, as presented in Table 2 . The model fitted well with the experimental data for all four temperature 386 sets with an $\mathrm{R}^{2}$ value greater than 0.96 showing reasonable agreement between the experimental 387 and calculated data. Figure 7 shows the kinetic data and compared with the experimental result. It 388 is observed that the activation energies of formation and decomposition of sugars decreased 389 significantly for [BMIM] $\mathrm{Cl}$ ionic liquid media compared with the hydrolysis that takes place in 390 aqueous media [31]. The activation energy of cellulose depolymerization to reducing sugars 391 calculated $\left(\mathrm{E}_{\mathrm{a} 1}=85.8 \mathrm{~kJ} \mathrm{~mol}^{-1}\right)$, is less than the calculated activation energy for acid hydrolysis of 392 cellulose in water $\left(\mathrm{Ea}_{1}=105-188 \mathrm{~kJ} \mathrm{~mol}^{-1}\right)$ [9]. The activation energy values reported in cellulose 393 hydrolysis using ionic liquid solvent falls in the range of 55 to $89 \mathrm{~kJ} \mathrm{~mol}^{-1}$ which depends on the 394 nature of the ionic liquid and the co-solvent effect [10].

395 Similarly, the activation energy for decomposition of reducing sugars in ionic liquid was lower $396\left(\mathrm{Ea} 2=42.5 \mathrm{~kJ}\right.$ mol-1) than aqueous media $\left(\mathrm{E}_{\mathrm{a} 2}=120 \mathrm{~kJ} \mathrm{~mol}^{-1}\right)$. The decrease in activation 397 energies for the consecutive reactions can be attributed to the ionic liquid's ionic nature, enhancing 398 the susceptibility of glycosidic bond cleavage to release the sugar monomers. The plot of $\ln (\mathrm{k}) \mathrm{vs}$. 399 1/T leads to a straight line with a slope of the fitting line indicating the activation energy and pre400 exponential factor is determined by the intercept of the fitting curve as shown in Figure 8 and 
401 reported in the literature [32] for both formation and decomposition of reducing sugar from the 402 depolymerization of cellulose.

403 4. Conclusion The inert nature of cellulose and insufficient knowledge in solid-solid reaction 404 systems make the heterogeneous catalytic conversion of cellulose ambitious. In our research, 405 porous zeolite materials ( H-ZSM-5) and ionic liquid have shown extraordinary ability to perform 406 as catalyst and catalyst support for cellulose conversion. It appears that the mechanism of action 407 of the zeolite catalyst is via the breaking of the glycosidic bonds in cellulose to release the glucose 408 monomers. The closeness of the acidic sites may be essential for cellulose hydrolysis than acidic 409 strength alone.

410 A kinetic study for MCC hydrolysis using the synergistic effect of [BMIM] $\mathrm{Cl}$ ionic liquid was 411 performed over H-ZSM-5. The catalyst was adequate for the MCC's depolymerization up to a yield 412 value of $70 \%$ TRS. [BMIM] $\mathrm{Cl}$ ionic liquid was highly influential in overcoming cellulosic 413 biomass's recalcitrance by breaking the extensive network of intra and inter-hydrogen bonding and 414 the strong acidity of H-ZSM-5 was able to break the beta-1, 4-glycosidic bond to release sugar 415 molecules. During depolymerization reaction, ionic liquid's presence significantly reduced the 416 activation energy of both the formation and decomposition of sugar obtained from the reaction.

417 The activation energy calculated in cellulose hydrolysis using H-ZSM-5 for a depolymerization 418 time of 180 min was found to be $85.8 \mathrm{~kJ}$ mol-1 while the decomposition of reducing sugars in 419 ionic liquid was found to be $42.5 \mathrm{~kJ}$ mol-1.Reference

420 [1] R. J. Chimentão, E. Lorente, F. Gispert-Guirado, F. Medina, and F. López, "Hydrolysis of 421 dilute acid-pretreated cellulose under mild hydrothermal conditions," Carbohydr. Polym., 422 vol. 111, pp. 116-124, 2014, doi: 10.1016/j.carbpol.2014.04.001. 
423 [2] W. Ji, Z. Shen, and Y. Wen, "Hydrolysis of wheat straw by dilute sulfuric acid in a continuous mode," Chem. Eng. J., vol. 260, pp. 20-27, 2015, doi: 10.1016/j.cej.2014.08.089.

426

427

428

429

430

431

432

433

434

435

436

437

438

439

440

441

442

443

444

[3] T. Auxenfans, S. Buchoux, K. Djellab, C. Avondo, E. Husson, and C. Sarazin, "Mild pretreatment and enzymatic saccharification of cellulose with recycled ionic liquids towards one-batch process," Carbohydr. Polym., vol. 90, no. 2, pp. 805-813, 2012, doi: 10.1016/j.carbpol.2012.05.101.

[4] Y. Chen, G. Li, F. Yang, and S. Zhang, "Mn / ZSM-5 participation in the degradation of cellulose under phosphoric acid media," Polym. Degrad. Stab., vol. 96, no. 5, pp. 863-869, 2011, doi: 10.1016/j.polymdegradstab.2011.02.007.

[5] C. Abels, K. Thimm, H. Wulfhorst, A. Christine, and M. Wessling, "Bioresource Technology Membrane-based recovery of glucose from enzymatic hydrolysis of ionic liquid pretreated cellulose," Bioresour. Technol., vol. 149, pp. 58-64, 2013, doi: 10.1016/j.biortech.2013.09.012.

[6] J. Wang, J. Xi, and Y. Wang, "Recent advances in the catalytic production of glucose from lignocellulosic biomass," Green Chem., vol. 17, no. 2, pp. 737-751, 2015, doi: 10.1039/C4GC02034K.

[7] J. Verendel, T. Church, and P. Andersson, "Catalytic One-Pot Production of Small Organics from Polysaccharides," Synthesis (Stuttg)., vol. 2011, no. 11, pp. 1649-1677, Apr. 2011, doi: $10.1055 / \mathrm{s}-0030-1260008$.

[8] H. T. Vo, V. T. Widyaya, J. Jae, H. S. Kim, and H. Lee, "Hydrolysis of ionic cellulose to glucose," Bioresour. Technol., vol. 167, pp. 484-489, 2014, doi: 
10.1016/j.biortech.2014.06.025.

446

447

448

449

450

451

452

453

454

455

456

457

458

459

460

461

462

463

464

465

[9] Y.-B. Huang and Y. Fu, "Hydrolysis of cellulose to glucose by solid acid catalysts," Green Chem., vol. 15, no. 5, p. 1095, 2013, doi: 10.1039/c3gc40136g.

[10] A. Brandt, J. Gräsvik, J. P. Hallett, and T. Welton, "Deconstruction of lignocellulosic biomass with ionic liquids," Green Chem., vol. 15, no. 3, pp. 550-583, 2013, doi: $10.1039 / \mathrm{c} 2 \mathrm{gc} 36364 \mathrm{j}$.

[11] Y. Fukaya, K. Hayashi, and H. Ohno, "Cellulose dissolution with polar ionic liquids under mild conditions: required factors for anions \{," no. Chart 1, pp. 44-46, 2008, doi: 10.1039/b713289a.

[12] X. Tong, Y. Ma, and Y. Li, "Applied Catalysis A : General Biomass into chemicals: Conversion of sugars to furan derivatives by catalytic processes," "Applied Catal. A, Gen., vol. 385, no. 1-2, pp. 1-13, 2010, doi: 10.1016/j.apcata.2010.06.049.

[13] S. Kassaye, C. Pagar, K. K. Pant, S. Jain, and R. Gupta, "Bioresource Technology Depolymerization of microcrystalline cellulose to value added chemicals using sulfate ion promoted zirconia catalyst," Bioresour. Technol., vol. 220, pp. 394-400, 2016, doi: 10.1016/j.biortech.2016.08.109.

[14] X. Cao et al., "Impact of regeneration process on the crystalline structure and enzymatic hydrolysis of cellulose obtained from ionic liquid.," Carbohydr. Polym., vol. 111, pp. 4003, Oct. 2014, doi: 10.1016/j.carbpol.2014.05.004.

[15] P. K. Rout, A. D. Nannaware, O. Prakash, A. Kalra, and R. Rajasekharan, "Synthesis of hydroxymethylfurfural from cellulose using green processes: A promising biochemical and 
biofuel feedstock," Chem. Eng. Sci., vol. 142, pp. 318-346, 2016, doi: 10.1016/j.ces.2015.12.002.

[16] S. Kassaye, K. K. Pant, and S. Jain, "Synergistic effect of ionic liquid and dilute sulphuric acid in the hydrolysis of microcrystalline cellulose," Fuel Process. Technol., vol. 148, pp. 289-294, 2016, doi: 10.1016/j.fuproc.2015.12.032.

[17] H. E. van der Bij and B. M. Weckhuysen, "Local silico-aluminophosphate interfaces within phosphated H-ZSM-5 zeolites.," Phys. Chem. Chem. Phys., vol. 16, no. 21, pp. 29-32, 2014, doi: 10.1039/c3cp54791d.

[18] N. Mimura, M. Okamoto, H. Yamashita, S. T. Oyama, and K. Murata, "Oxidative dehydrogenation of ethane over Cr/ZSM-5 catalysts using $\mathrm{CO} 2$ as an oxidant.," J. Phys. Chem. B, vol. 110, no. 43, pp. 21764-70, 2006, doi: 10.1021/jp0619661.

[19] H. Cai, C. Li, A. Wang, G. Xu, and T. Zhang, “Applied Catalysis B : Environmental Zeolitepromoted hydrolysis of cellulose in ionic liquid, insight into the mutual behavior of zeolite , cellulose and ionic liquid," "Applied Catal. B, Environ., vol. 123-124, pp. 333-338, 2012, doi: 10.1016/j.apcatb.2012.04.041.

[20] H. Liu, H. Wei, W. Xin, and C. Song, "Differences between Zn / HZSM-5 and Zn / HZSM11 zeolite catalysts in alkylation of benzene with dimethyl ether," J. Energy Chem., vol. 23, no. 5, pp. 617-624, 2014, doi: 10.1016/S2095-4956(14)60192-3.

[21] A. M. Santa Arango, C. M. Escobar Garcés, J. L. Agudelo Valderrama, A. Guzmán Monsalve, L. A. Palacio Santos, and A. Echavarría Isaza, "Oligomerization of propene over ZSM-5 modified with Cr and W," Rev. Fac. Ing., no. 57, pp. 57-65, 2011. 
[22] I. G. Baek, S. J. You, and E. D. Park, "Bioresource Technology Direct conversion of cellulose into polyols over Ni / W / SiO 2 -Al 2 O 3," Bioresour. Technol., vol. 114, pp. 684-690, 2012, doi: 10.1016/j.biortech.2012.03.059.

[23] S. Bali, M. A. Tofanelli, R. D. Ernst, and E. M. Eyring, "Chromium ( III ) catalysts in ionic liquids for the conversion of glucose to 5- ( hydroxymethyl ) furfural ( HMF ): Insight into metal catalyst: ionic liquid mediated conversion of cellulosic biomass to biofuels and chemicals," Biomass and Bioenergy, vol. 42, no. Iii, pp. 224-227, 2012, doi: 10.1016/j.biombioe.2012.03.016.

[24] H. Zhao, J. E. Holladay, H. Brown, and Z. C. Zhang, "Reports 8.," vol. 113409, no. 2005, 2006.

[25] H. Xu et al., "Dehydration of fructose into 5-hydroxymethylfurfural by high stable ordered mesoporous zirconium phosphate," Fuel, vol. 145, pp. 234-240, 2015, doi: 10.1016/j.fuel.2014.12.072.

[26] L. Hu, Z. Wu, J. Xu, Y. Sun, L. Lin, and S. Liu, "Zeolite-promoted transformation of glucose into 5-hydroxymethylfurfural in ionic liquid," Chem. Eng. J., vol. 244, pp. 137144, 2014, doi: 10.1016/j.cej.2014.01.057.

[27] J. F. Saeman, "Hydrolysis of Cellulose and Decomposition of Sugars in Dilute Acid at High Temperature," Ind. Eng. Chem., vol. 37, no. 9, pp. 43-52, 1945, doi: Doi 10.1021/Ie50421a009.

[28] L. Negahdar, I. Delidovich, and R. Palkovits, “Aqueous-phase hydrolysis of cellulose and hemicelluloses over molecular acidic catalysts: Insights into the kinetics and reaction mechanism," Appl. Catal. B Environ., vol. 184, pp. 285-298, 2016, doi: 
510

511

512

513

514

515

516

517

518

519

520

521

522

523

[29] F. Guo, Z. Fang, C. C. Xu, and R. L. Smith, "Solid acid mediated hydrolysis of biomass for producing biofuels," Prog. Energy Combust. Sci., vol. 38, no. 5, pp. 672-690, 2012, doi: 10.1016/j.pecs.2012.04.001.

[30] L. Hu et al., "Catalytic conversion of carbohydrates into 5-hydroxymethylfurfural over cellulose-derived carbonaceous catalyst in ionic liquid.," Bioresour. Technol., vol. 148, pp. 501-7, Nov. 2013, doi: 10.1016/j.biortech.2013.09.016.

[31] A. J. Kunov-Kruse, A. Riisager, S. Saravanamurugan, R. W. Berg, S. B. Kristensen, and R. Fehrmann, "Revisiting the Bronsted acid catalysed hydrolysis kinetics of polymeric carbohydrates in ionic liquids by in situ ATR-FTIR spectroscopy," Green Chem., vol. 15, no. 10, pp. 2843-2848, 2013, doi: 10.1039/c3gc41174e.

[32] M. Mohan, T. Banerjee, and V. V Goud, "Hydrolysis of bamboo biomass by subcritical water treatment.," Bioresour. Technol., vol. 191, pp. 244-252, 2015, doi: 10.1016/j.biortech.2015.05.010. 
Table 1. BET surface area analysis of H-ZSM-5 and Cr/H-ZSM-5 catalysts

\begin{tabular}{|c|c|}
\hline Catalyst Type & BET surface area $\left(\mathbf{m}^{2} / \mathbf{g}\right)$ \\
\hline H-ZSM-5 & 270.0 \\
\hline Cr/H-ZSM-5 & 248.2 \\
\hline
\end{tabular}

Table 2. Kinetic rate constants at different temperatures

\begin{tabular}{ccc}
\hline Temperature $\left({ }^{\circ} \mathrm{C}\right)$ & $\mathrm{k}_{1}\left(\mathrm{~min}^{-1}\right)$ & $\mathrm{k}_{2}\left(\mathrm{~min}^{-1}\right)$ \\
\hline 140 & 0.0010 & 0.0006 \\
160 & 0.0042 & 0.0019 \\
180 & 0.0094 & 0.0020 \\
200 & 0.0244 & 0.0035 \\
\hline
\end{tabular}


Figures

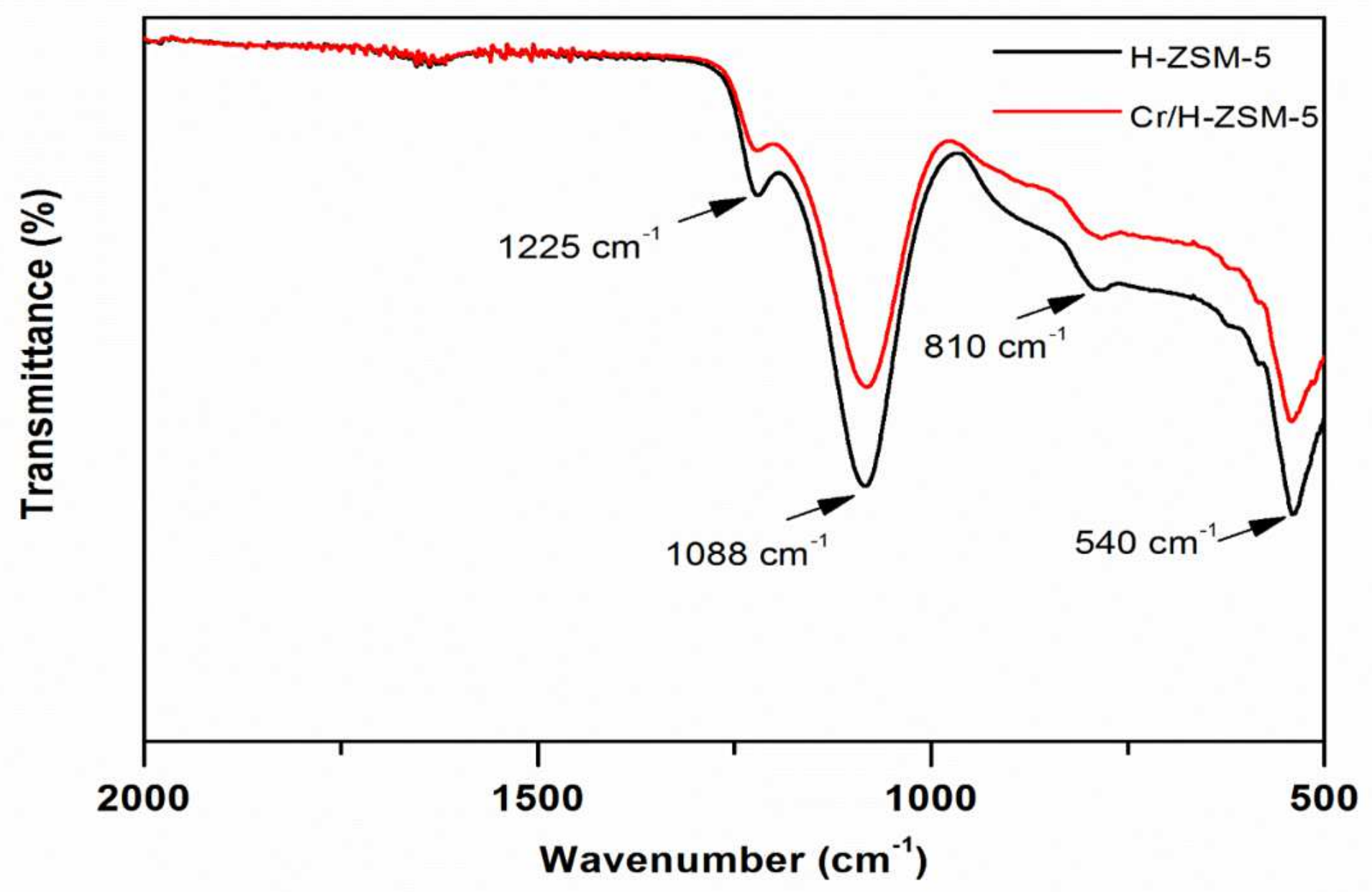

Figure 1

FTIR analysis of $\mathrm{H}-\mathrm{ZSM}-5$ and $\mathrm{Cr} / \mathrm{H}-\mathrm{ZSM}-5$ catalysts 


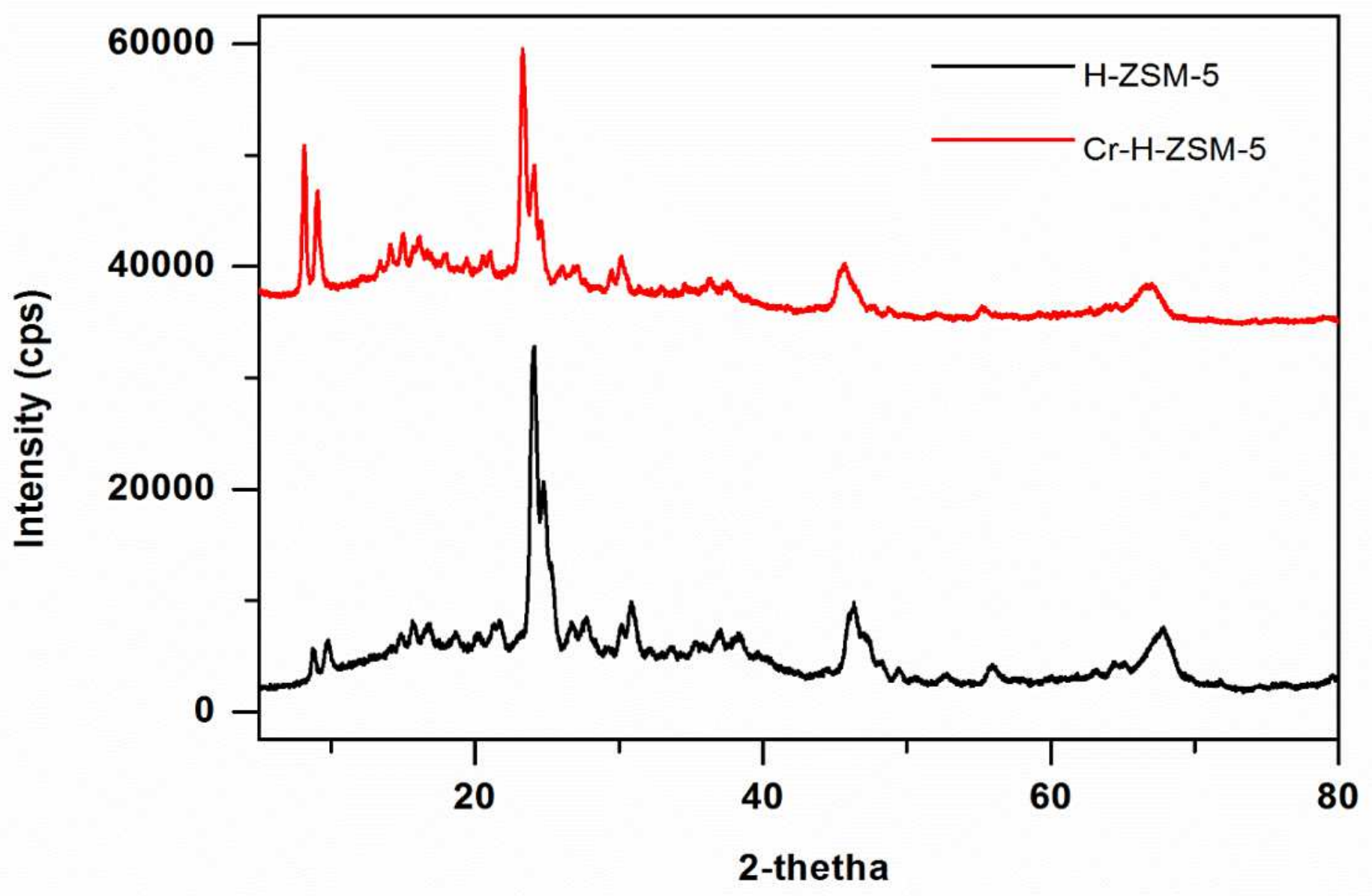

Figure 2

XRD pattern of $\mathrm{H}-\mathrm{ZSM}-5$ and $\mathrm{Cr} / \mathrm{H}-\mathrm{ZSM}-5$ catalysts 


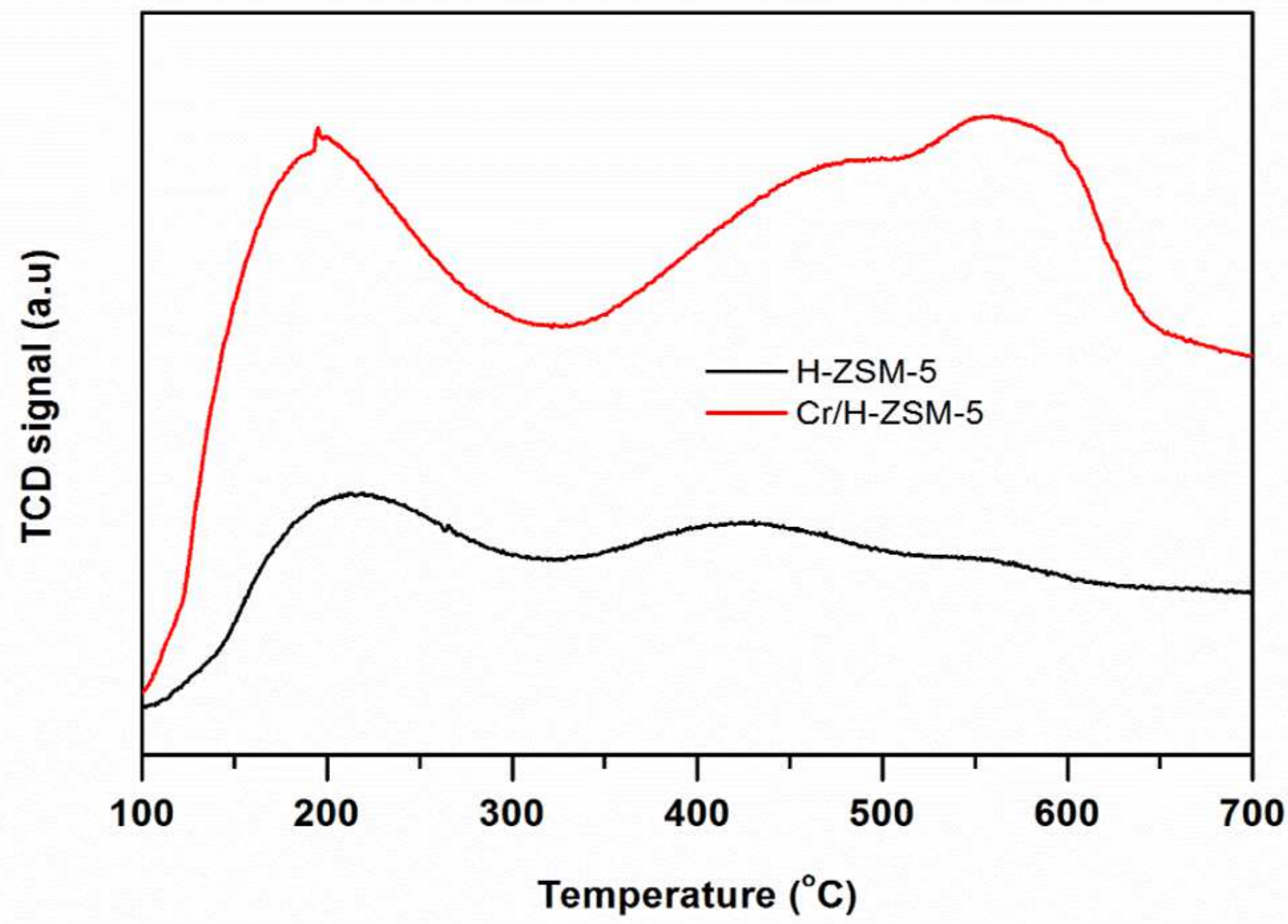

Figure 3

Ammonia-TPD analysis of $\mathrm{H}-\mathrm{ZSM}-5$ and $\mathrm{Cr} / \mathrm{H}-\mathrm{ZSM}-5$ catalysts 


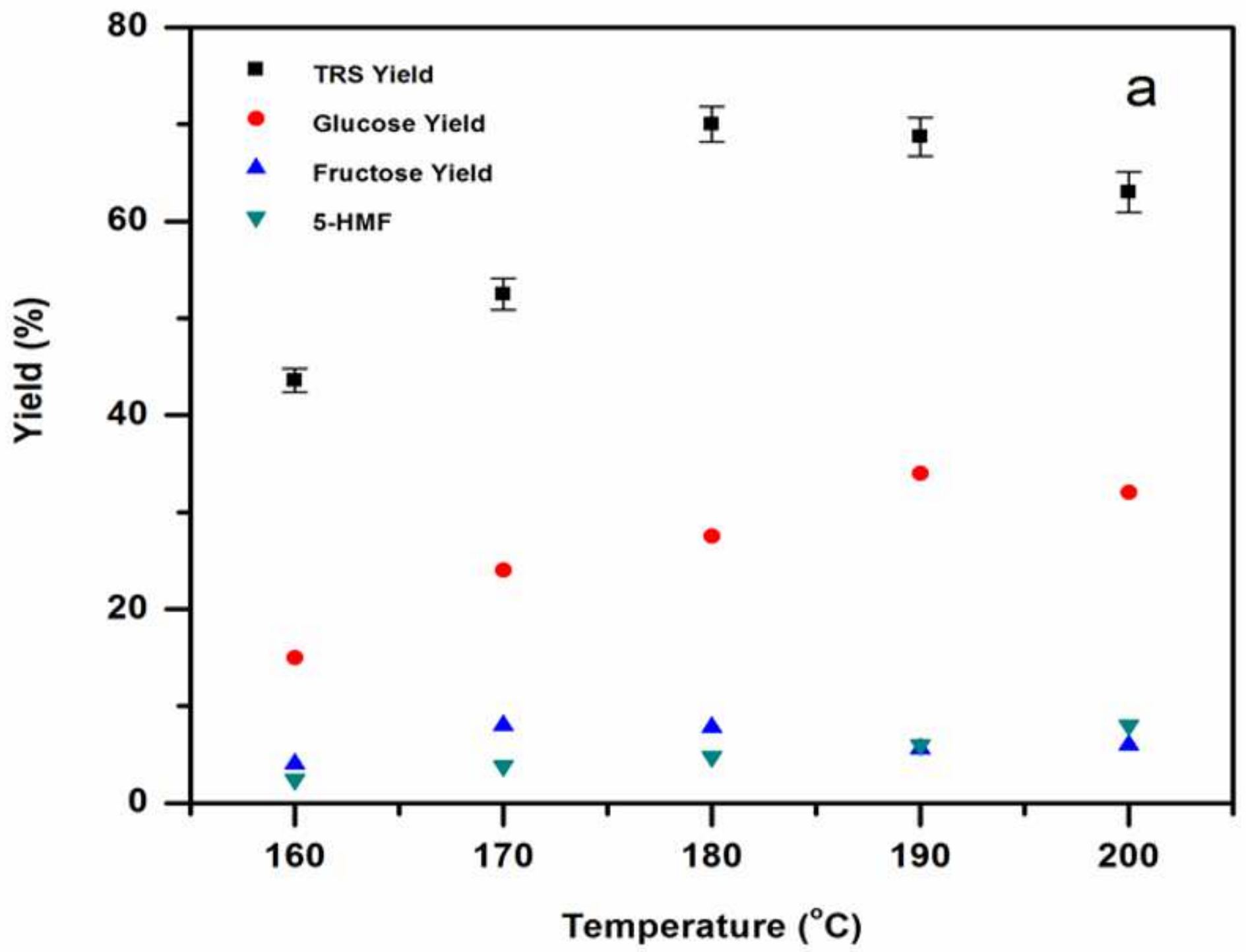

Figure 4

Effect of hydrolysis temperature on TRS yield (catalyst to substrate ratio of 2:1 (w/w) and $180 \mathrm{~min}$ of reaction time) 


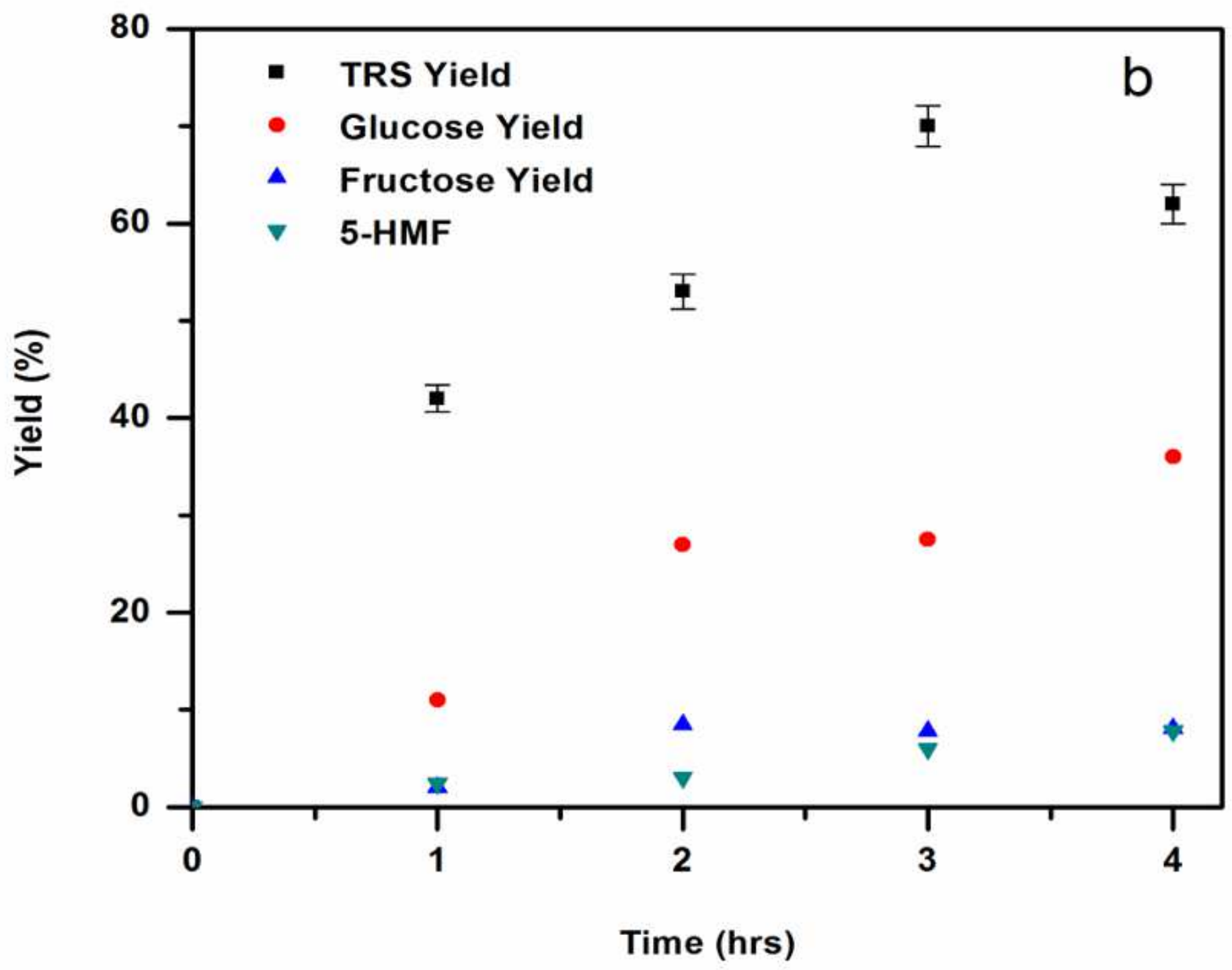

Figure 5

Effect of hydrolysis time on yield of TRS (temperature 180 oC, catalyst to substrate ratio of 2:1 $(\mathrm{w} / \mathrm{w})$ )

1-Butyl-3-methylimidazolium chloride

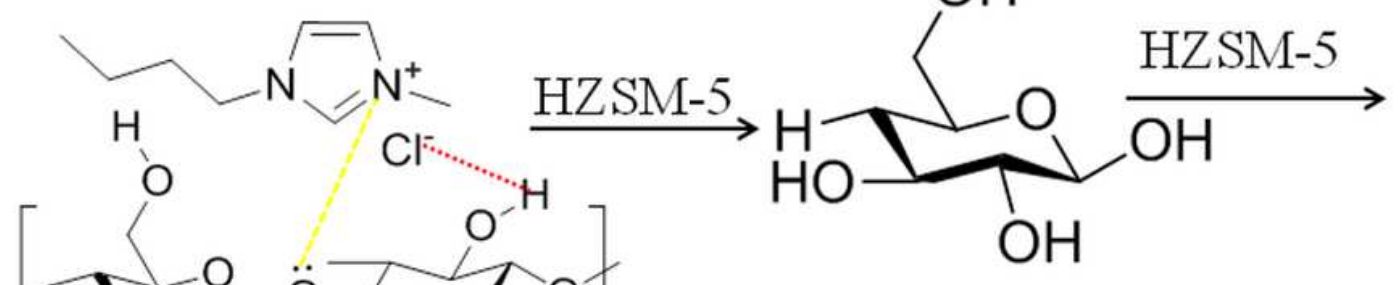

Sugar
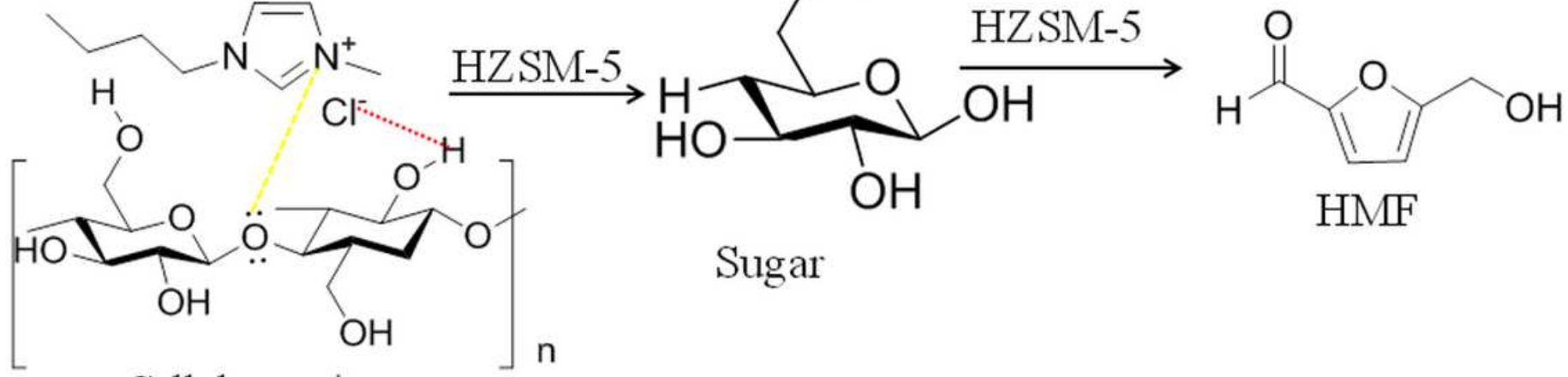

Cellulose unit 
Figure 6

Mechanism of Cellulose Hydrolysis over $\mathrm{H}-\mathrm{ZSM}-5$ catalyst in the presence of [BMIM] Cl ionic liquid
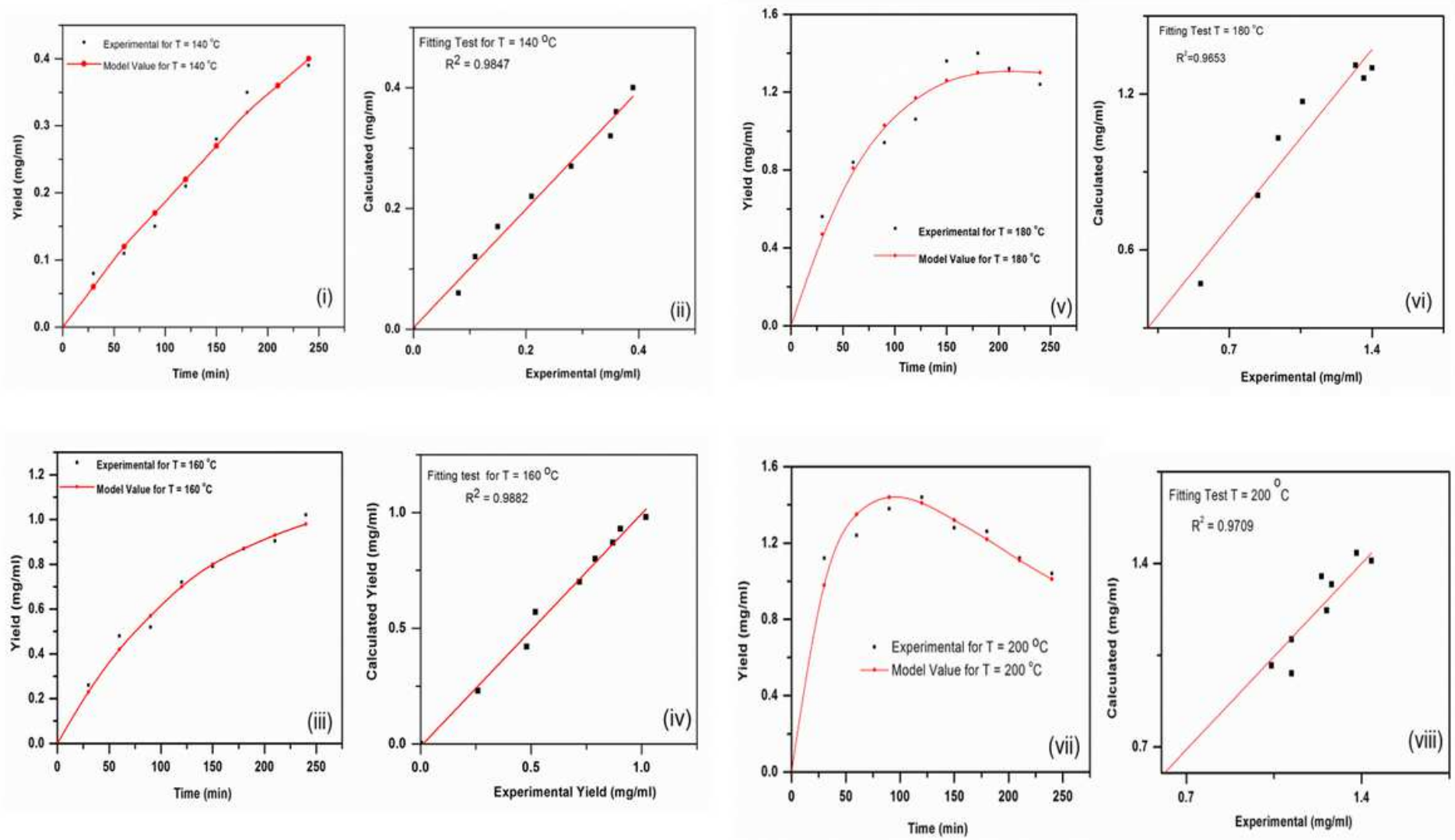

Figure 7

Kinetic modelling of cellulose hydrolysis using $\mathrm{H}-\mathrm{ZSM}-5$ catalyst in [BMIM] Cl-water media 

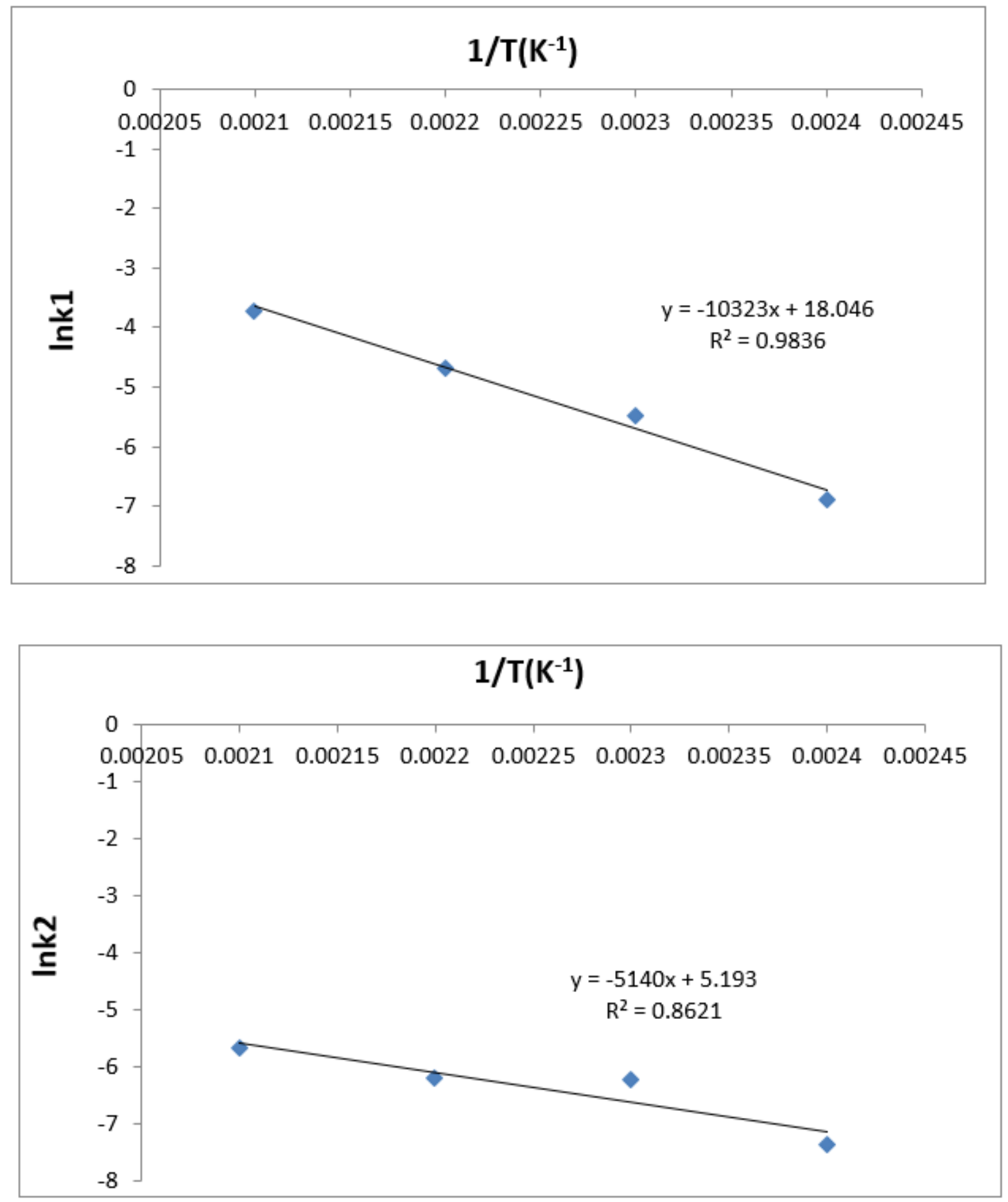

Figure 8

Determination of rate constants for cellulose hydrolysis using $\mathrm{H}-\mathrm{ZSM}-5$ catalyst in [BMIM] Cl 